\title{
The Association Between the Use of Antenatal Care Smartphone Apps in Pregnant Women and Antenatal Depression: Cross-Sectional Study
}

Yushi Mo ${ }^{1}$, BS; Wenjie Gong ${ }^{1}$, PhD; Joyce Wang ${ }^{1}$, BA; Xiaoqi Sheng ${ }^{2}$, MS; Dong R Xu ${ }^{3}, \mathrm{PhD}, \mathrm{MPP}$

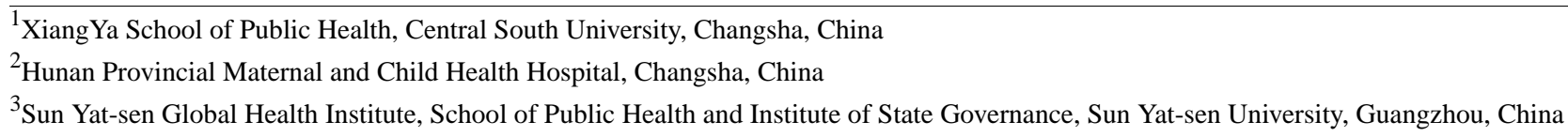

Corresponding Author:

Wenjie Gong, PhD

Xiang Ya School of Public Health

Central South University

238 Shangmayuanling Lane

Xiangya Road, KaiFu District

Changsha,

China

Phone: 8613607445252

Email: gongwenjie@csu.edu.cn

\section{Abstract}

Background: Antenatal care smartphone apps are increasingly used by pregnant women, but studies on their use and impact are scarce.

Objective: This study investigates the use of antenatal care apps in pregnant women and explores the association between the use of these apps and antenatal depression.

Methods: This study used a convenient sample of pregnant women recruited from Hunan Provincial Maternal and Child Health Hospital in November 2015. The participants were surveyed for their demographic characteristics, use of antenatal care apps, and antenatal depression. Factors that influenced antenatal pregnancy were analyzed using logistic regression.

Results: Of the 1304 pregnant women, $71.31 \%$ (930/1304) used antenatal care apps. Higher usage of apps was associated with urban residency, nonmigrant status, first pregnancy, planned pregnancy, having no previous children, and opportunity to communicate with peer pregnant women. The cutoff score of the Edinburgh Postnatal Depression Scale was 10, and 46.11\% (601/1304) of the pregnant women had depression. Logistic regression showed that depression was associated with the availability of disease-screening functions in the apps (odds ratio (OR) 1.78, 95\% CI 1.03-3.06) and spending 30 minutes or more using the app (OR 2.05, 95\% CI 1.19-3.52). Using apps with social media features was a protective factor for antenatal depression (OR $0.33,95 \%$ CI $0.12-0.89$ ).

Conclusions: The prevalence of the use of prenatal care apps in pregnant women is high. The functions and time spent on these apps are associated with the incidence of antenatal depression.

(JMIR Mhealth Uhealth 2018;6(11):e11508) doi: 10.2196/11508

\section{KEYWORDS}

antenatal care; antenatal depression; app; mobile phone

\section{Introduction}

With the advent of the information age, the use of smartphones and apps is becoming more common. It is predicted that the world's smartphone ownership rate will reach $66 \%$ in 2018 , and China will have 1.3 billion smartphone users [1]
Meanwhile, the number of global app downloads has exceeded to 175 billion in 2017, with China becoming the world's largest smartphone app market. In the $4^{\text {th }}$ quarter of 2017 alone, the usage time of Chinese users of iOS, Google Play, and third-party Android apps reached 200 billion hours [2]. China's huge smartphone user base and high accessibility of Wi-Fi or $4 \mathrm{G}$ 
have made people's frequent use of mobile apps a reality, and the use of these apps in health care is worthy of attention. As of December 2016, the number of people using the Internet for health purposes in China reached 195 million, accounting for $26.6 \%$ of all Internet users. Among them, the medical information inquiry use rate was the highest, accounting for $10.8 \%$ [3]. Consultation in obstetrics and gynecology was also the most used service in a leading Web-based medical consultation app in China [4]. Due to high demand and adherence, pregnant women have become a key target group for app developers.

Antenatal care apps (acAPPs) are a type of smartphone apps that provide prenatal care services and information targeting prepregnant and pregnant women. It is a new way of channeling information and interpersonal interaction in the current era of mobile technology development, which has been widely accepted [5,6]. A study in the United States showed that apps for women's health and pregnancy accounted for $7 \%$ of all kinds of apps [7]. We found 110 maternal health-related apps on the Chinese app market. Functions of these apps were diverse although the provision of maternity-related information to pregnant women was the major one. This form of health guidance is superior to traditional methods and can even improve the quality of pregnancy care in areas with scarce medical resources [5,8-10]. Many apps also have social functions, professional counseling functions, and special tools, such as calculation of fetal movement, calculation of due date, and measurement of changes in body weight. These self-monitored health status functions can be used to track pregnant women's health $[5,8,11,12]$.

Although acAPPs are widely used, research on the relationship of such use with user health and especially mental health is scarce. At present, existing studies mainly focus on the use of apps for monitoring or intervening mental disorders. Sensors and apps of smartphones have been used to predict daily mood [13,14], detect depression [15-18], intervene depression [19], relieve pressure [20], and treat depression [18,19,21]. Mental health and app-related researches are even rarer, and their use and effect evaluation among pregnant women have not been reported. Pregnancy is a period of high incidence of mental disorders, which increases not only the risk of postpartum depression but also its severity [22-25].

There may be intergenerational negative effects from both physical and environmental aspects. Therefore, gestational depression has received much attention in recent years and was included in the category of perinatal depression by the Diagnostic and Statistical Manual of Mental Disorders, Fifth Edition, in 2013. The use period of acAPPs overlaps with the occurrence of gestational depression. Whether there is a certain relationship between the two and what that relationship may be are the factors not only worthy of researchers' attention in the field of maternal and child health but also important information for acAPP developers.
This study investigates the use of acAPPs in pregnant women at a specialized hospital for obstetrics and gynecology, examines antenatal depression, and explores the correlation between the use of acAPPs and mental health during pregnancy. These results can provide direction and theoretical basis for the development of future acAPPs.

\section{Methods}

\section{Sample}

Participants $(\mathrm{N}=1304)$ were pregnant women who visited the maternity department of the Maternal and Child Health Hospital of Hunan Province from November 16, 2015, to November 21, 2015.

\section{Procedure}

A convenience sampling approach was employed. During the investigation period, we explained the research purpose, content, and possible risks and benefits to all pregnant women who visited the Maternity Department of the Hunan Provincial Maternal and Child Health Hospital and invited them to participate in the survey. Questionnaires were issued to pregnant women aged 18 years and over who gave verbal consent. Women who were unable to understand the contents of the questionnaire were excluded from this study. We issued 1800 questionnaires, recollected 1520 questionnaires, and ultimately determined that 1304 questionnaires were valid, corresponding to an effective recovery rate of $72.44 \%$ (1304/1800). Flow of participants is presented in Figure 1. The study has been approved by the institutional review board of the Institute of Nursing and Behavioral Medicine Research, School of Nursing, Central South University (\# 2015062).

\section{Measures}

A self-developed questionnaire, optimized after preinvestigation, was used to collect information on demographics (eg, birth year, ethnicity, type of birthplace and residence, migrant population status, family income, and educational levels) and acAPP usage (eg, acAPP download channel, start usage time, duration of each use, frequency of use, and common functions).

The Edinburgh Postnatal Depression Scale (EPDS) is commonly used to screen for perinatal depression. It is a 10-item self-rated questionnaire, with each item scored from 0 to 3 , giving a score ranging from 0 to 30 . EPDS used to screen for antenatal depression in this study was translated by Wang Yuqiong [26], and several studies [27-30] have validated that it can be used for perinatal depression screening, including antenatal depression. The critical value was 9.5.

\section{Statistical Methods}

Different usages of acAPPs among pregnant women were analyzed using the chi-square test. The association between acAPP usage and antenatal depression was analyzed using binary logistic regression. 
Figure 1. Flow of participants.

\begin{tabular}{|l|l|l|l|l|}
\hline $\begin{array}{l}\text { Received } \\
\text { informed consent, } \\
\text { Issued } \\
\text { questionnaire } \\
(n=1800)\end{array}$ & $\rightarrow \begin{array}{l}\text { Recollected } \\
\text { questionnaire } \\
(n=1520)\end{array}$ & $\begin{array}{l}\text { Excluded invalid } \\
\text { questionnaires (missing } \\
\text { more than 40\%) }\end{array}$ \\
\end{tabular}

\section{Results}

\section{Demographic Information of Pregnant Women}

The demographic characteristics of the sample and univariate analysis are shown in Table 1 . The average age of the pregnant women was 28.66 (SD 3.964) years. They mainly lived in a city, were nonmigrants, had a family monthly income of 5000-10,000 yuan (US \$785-1570), and had completed undergraduate or college education. More than half of the pregnant women were pregnant for the first time and about two-thirds had no previous children.

\section{Use of Antenatal Care Apps}

In this study, $71.31 \%$ (930/1304) of the pregnant women used acAPPs. Higher usage of acAPPs was associated with urban residency, nonmigrant status, first pregnancy, planned pregnancy, having no previous children, and opportunity to communicate with peer pregnant women. There were differences in the utilization rate of acAPPs among pregnant women of different ages, family incomes, and education levels $(P=.02$, $P=.001, \quad P<.001$, respectively). Usage of acAPPs among pregnant women aged 25-29 years was higher than that among women aged $\geq 35$ years. App usage among those with family incomes in the 5000-10,000 renminbi (RMB)/month and 10,000-15,000 RMB/month brackets was higher than that among those with family incomes less than or equal to 5000 $\mathrm{RMB} /$ month. Usage among women with education levels of junior high school and below was lower than that among women with higher education levels $(P<.001$; see Table 2$)$.

When choosing the kind of acAPP, pregnant women paid the most attention to the user rating and information content of acAPPs, and app stores and official websites were the main channels of acAPP downloads (Table 3). Apps commonly used by pregnant women are shown in Table 4. Baobaoshu, accounting for $45.8 \%$ of the total usage, was the most commonly used acAPP among pregnant women, followed by Meiyou and Huaiyunguanjia (14.9\% and 7.4\%, respectively). Other apps included Haoyunma, Yunqiguanjia, Yunqitixing, Qinbaobao, Lamabang, and more than 10 other kinds of acAPPs.

Among the 10 possible functions of the health care acAPP during pregnancy, antenatal care tips, health information, changes in pregnancy records, and dietary recommendations were the most commonly used functions by pregnant women (Table 5). Moreover, 67.1\% (619/930) of the pregnant women started using the acAPP mainly 12 weeks after pregnancy. Almost half $(455 / 930,49.1 \%)$ used acAPPs 1-2 times per day, the average duration of each use was mainly 15 minutes, and $70.86 \%(659 / 930)$ of the pregnant women had been using acAPPs for 3-12 months (Table 6). Comprehensive, informative, user-friendly, and reliable content were features most users said appealed to them about acAPPs. Increasing knowledge was the greatest benefit pregnant women reported receiving from using acAPPs (Figure 2).

\section{Antenatal Depression and Its Association With Using Antenatal Care Apps}

Among pregnant women, 46.16\% (602/1304) screened positive for depression by EPDS. Controlling for demographic characteristics and pregnancy situations, logistic regression showed that functions of and time spent on these apps were associated with the incidence of antenatal depression (Table 7). Moreover, acAPPs containing disease-screening functions and using apps for more than 30 minutes at a time were positively related to the occurrence of depression. AcAPPs containing social functions were negatively correlated with depression. 
Table 1. Demographic information of pregnant women.

\begin{tabular}{|c|c|}
\hline Item & Value, $\mathrm{n}(\%)$ \\
\hline \multicolumn{2}{|l|}{ Age, years } \\
\hline$<25$ & $146(11.1)$ \\
\hline $25-29$ & $685(52.1)$ \\
\hline $30-34$ & $322(24.5)$ \\
\hline$\geq 35$ & $126(9.6)$ \\
\hline Missing & $35(2.7)$ \\
\hline \multicolumn{2}{|l|}{ Residence } \\
\hline City & $858(65.3)$ \\
\hline Rural area & $310(23.6)$ \\
\hline Missing & $146(11.1)$ \\
\hline \multicolumn{2}{|l|}{ Migrant population } \\
\hline Yes & $313(23.8)$ \\
\hline No & $933(71.0)$ \\
\hline Missing & $68(5.2)$ \\
\hline \multicolumn{2}{|c|}{ Family income, renminbi/month (US \$/month) } \\
\hline$\leq 5000$ yuan $(785)$ & $252(19.2)$ \\
\hline $5000-10,000$ yuan $(785-1570)$ & $674(51.3)$ \\
\hline $10,000-15,000$ yuan $(1570-2355)$ & $192(14.6)$ \\
\hline$>15,000$ yuan $(2355)$ & $110(8.4)$ \\
\hline Missing & $86(6.5)$ \\
\hline \multicolumn{2}{|l|}{ Education level } \\
\hline Junior high school and below & $80(6.1)$ \\
\hline High school or secondary school & $236(18.0)$ \\
\hline Undergraduate or college & $729(60.3)$ \\
\hline Master's and above & $101(7.7)$ \\
\hline Missing & $105(8.0)$ \\
\hline \multicolumn{2}{|l|}{ First pregnancy } \\
\hline Yes & $713(56.4)$ \\
\hline No & $552(42.0)$ \\
\hline Missing & $49(3.7)$ \\
\hline \multicolumn{2}{|l|}{ Planned pregnancy } \\
\hline Yes & $841(64.0)$ \\
\hline No & $431(32.8)$ \\
\hline Missing & $42(3.2)$ \\
\hline \multicolumn{2}{|l|}{ Previous children } \\
\hline Yes & $427(32.5)$ \\
\hline No & $865(65.8)$ \\
\hline Missing & $22(1.7)$ \\
\hline \multicolumn{2}{|c|}{ Opportunity to communicate with peer pregnant women } \\
\hline Have & $1054(80.2)$ \\
\hline Do not have & 245 (18.6) \\
\hline Missing & $15(1)$ \\
\hline
\end{tabular}


Table 2. Different usages of antenatal care apps among pregnant women.

\begin{tabular}{|c|c|c|c|c|c|}
\hline Item & Using antenatal care app, $\mathrm{n}(\%)$ & Not using antenatal care app, $\mathrm{n}(\%)$ & $\chi^{2}$ & $d f^{\mathrm{a}}$ & $P$ value \\
\hline Age, years & & & 9.6 & 3 & 0.02 \\
\hline$<25$ & $100(11.0)$ & $46(12.5)$ & & & \\
\hline $25-29$ & $500(54.8)$ & $185(50.4)$ & & & \\
\hline $30-34$ & $236(25.9)$ & $86(23.4)$ & & & \\
\hline$\geq 35$ & $76(8.3)$ & $50(13.6)$ & & & \\
\hline Residence & & & 11.7 & 1 & 0.001 \\
\hline City & $636(76.3)$ & $222(66.5)$ & & & \\
\hline Rural area & $198(23.7)$ & $112(33.5)$ & & & \\
\hline Migrant population & & & 11.2 & 1 & 0.001 \\
\hline Yes & $203(22.6)$ & $110(31.7)$ & & & \\
\hline No & $696(77.4)$ & $237(68.3)$ & & & \\
\hline Family income, renminbi/month (US & & & 17.3 & 3 & 0.001 \\
\hline$\leq 5000$ yuan $(785)$ & $155(17.6)$ & $97(28.1)$ & & & \\
\hline $5000-10,000$ yuan $(785-1570)$ & $506(57.3)$ & $168(48.7)$ & & & \\
\hline $10,000-15,000$ yuan $(1570-2355)$ & $142(16.1)$ & $50(14.5)$ & & & \\
\hline$>15,000$ yuan $(2355)$ & $80(9.1)$ & $30(8.7)$ & & & \\
\hline Education level & & & 56.5 & 3 & $<0.001$ \\
\hline Junior high school and below & $30(3.5)$ & $50(14.2)$ & & & \\
\hline High school or secondary school & $155(18.1)$ & $81(23.0)$ & & & \\
\hline Undergraduate or college & $590(68.8)$ & $202(57.4)$ & & & \\
\hline Master's and above & $82(9.6)$ & $19(5.4)$ & & & \\
\hline First pregnancy & & & 8.8 & 1 & 0.003 \\
\hline Yes & $531(59.0)$ & $182(49.9)$ & & & \\
\hline No & $369(41.0)$ & $183(50.1)$ & & & \\
\hline Planned pregnancy & & & 4.9 & 1 & 0.03 \\
\hline Yes & $616(68.0)$ & $225(61.5)$ & & & \\
\hline No & $290(32.0)$ & $141(38.5)$ & & & \\
\hline Previous children & & & 12.2 & 1 & $<0.001$ \\
\hline Yes & $278(30.2)$ & $149(40.3)$ & & & \\
\hline No & $664(69.8)$ & $221(59.7)$ & & & \\
\hline \multicolumn{2}{|c|}{ Opportunity to communicate with peer pregnant women } & & 10.9 & 1 & 0.001 \\
\hline Have & $774(83.4)$ & $280(75.5)$ & & & \\
\hline Did not have & $154(16.6)$ & $91(24.5)$ & & & \\
\hline
\end{tabular}

${ }^{\mathrm{a}} d f$ : degrees of freedom. 
Table 3. Download channels of antenatal care apps.

\begin{tabular}{ll}
\hline Download variables & Value, $\mathrm{n}(\%)$ \\
\hline Emphasis when selecting antenatal care app & $490(53.1)$ \\
$\quad$ Information content & $385(41.7)$ \\
User rating & $178(19.3)$ \\
Comprehensive ranking & $137(14.8)$ \\
Download times & $116(12.6)$ \\
Scoring & $19(2.1)$ \\
Other & $14(1.5)$ \\
Memory occupied & \\
Download channel & $548(59.7)$ \\
App stores & $333(36.3)$ \\
Official website search & $19(2.1)$ \\
Pop-up connection & $18(2.0)$ \\
Other & \\
\hline
\end{tabular}

Table 4. Common antenatal care apps.

\begin{tabular}{ll}
\hline App name & Value, n (\%) \\
\hline Baobaoshu & $426(45.8)$ \\
Meiyou & $139(14.9)$ \\
Huaiyunguanjia & $69(7.4)$ \\
Mamabang & $42(4.5)$ \\
Yunqibanlv & $21(2.2)$ \\
Baobaozhidao & $21(2.2)$ \\
Yunqitixing & $15(1.6)$ \\
Others & $45(4.8)$ \\
\hline
\end{tabular}

Table 5. Common functions of antenatal care apps.

\begin{tabular}{ll}
\hline Functions & Common functions, $\mathrm{n}(\%)$ \\
\hline Health knowledge education & $134(33.3)$ \\
Changes during pregnancy record & $104(25.9)$ \\
Antenatal care tips & $94(23.5)$ \\
Diet recommendations & $88(21.9)$ \\
Answers and questions & $37(9.2)$ \\
Instant communication & $21(5.2)$ \\
Trading platform & $17(4.2)$ \\
Disease screening & $11(2.7)$ \\
Hospital related & $9(2.2)$ \\
Make friends & $5(1.2)$ \\
\hline
\end{tabular}


Table 6. Timing of using antenatal care apps.

\begin{tabular}{|c|c|}
\hline Time & Value, $\mathrm{n}(\%)$ \\
\hline \multicolumn{2}{|l|}{ Start time } \\
\hline Before pregnancy & $189(20.5)$ \\
\hline Within 12 weeks of gestation & $619(67.1)$ \\
\hline $12-27$ weeks of gestation & $103(11.2)$ \\
\hline After 27 weeks of pregnancy & $12(1.3)$ \\
\hline \multicolumn{2}{|l|}{ Frequency } \\
\hline 1-7 times/week & $326(35.2)$ \\
\hline 1-2 times/day & $457(49.4)$ \\
\hline$\geq 3$ times/day & $128(13.8)$ \\
\hline Other & $15(1.6)$ \\
\hline \multicolumn{2}{|l|}{ Average duration of each use } \\
\hline$\leq 15$ minute & $455(49.1)$ \\
\hline 15-30 minute & $394(42.5)$ \\
\hline $30-60$ minute & $56(6.0)$ \\
\hline$\geq 1$ hour & $21(2.3)$ \\
\hline \multicolumn{2}{|c|}{ Longest duration of antenatal care app retainment } \\
\hline$<3$ months & $188(20.4)$ \\
\hline $3-6$ months & $350(38.0)$ \\
\hline 6-12 months & $309(33.5)$ \\
\hline$>1$ year & $75(8)$ \\
\hline
\end{tabular}

Figure 2. Benefits of using antenatal care apps.

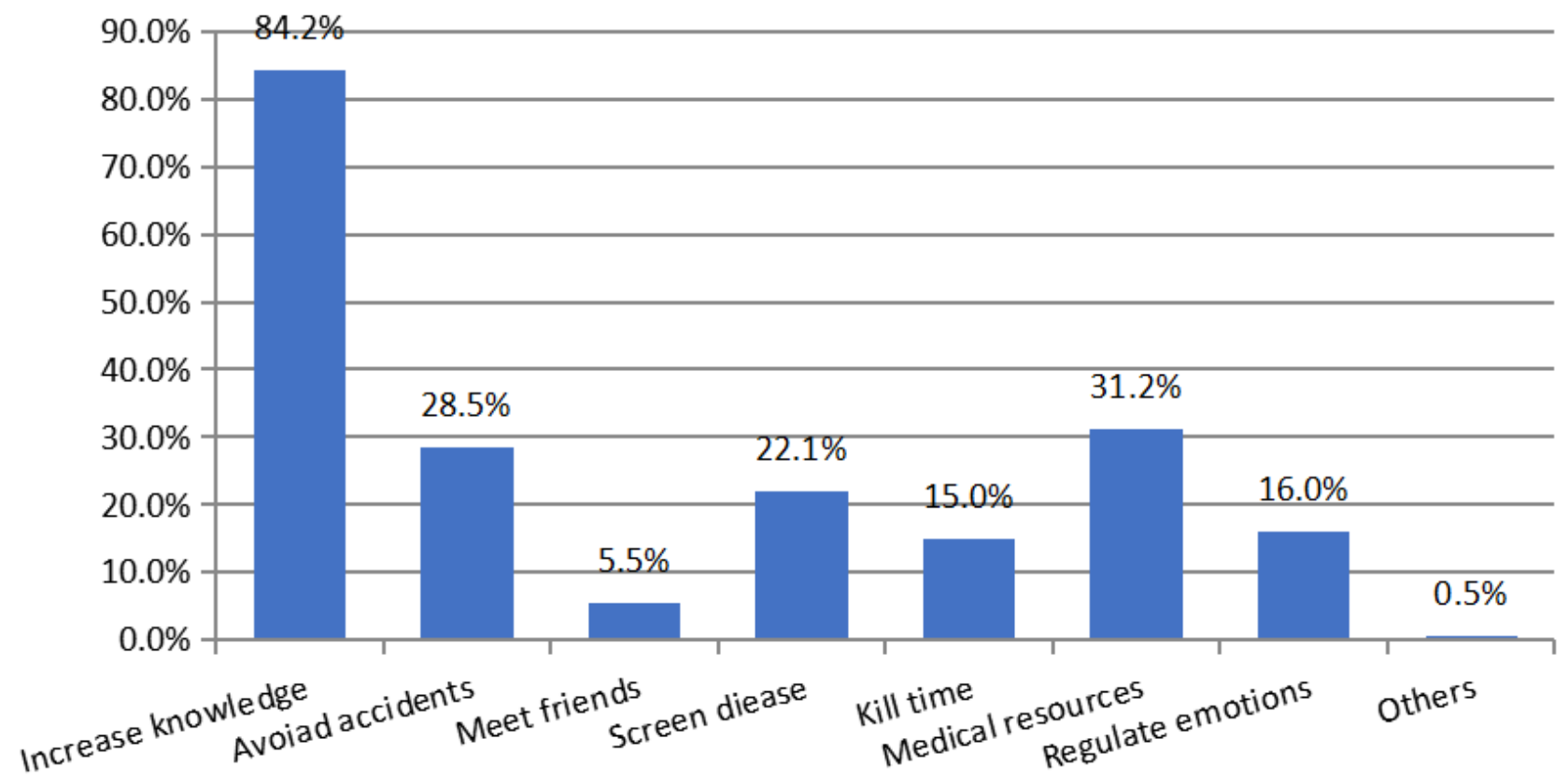


Table 7. Factors influencing antenatal depression.

\begin{tabular}{|c|c|c|c|c|c|c|c|}
\hline \multirow[t]{2}{*}{ Factors } & \multirow[t]{2}{*}{$\mathrm{B}$} & \multirow[t]{2}{*}{ Wals } & \multirow[t]{2}{*}{$d f^{\mathrm{a}}$} & \multirow[t]{2}{*}{$P$ value } & \multirow[t]{2}{*}{ Odds ratio } & \multicolumn{2}{|c|}{$95 \% \mathrm{CI}$} \\
\hline & & & & & & Lower & Upper \\
\hline \multicolumn{8}{|l|}{ Disease-screening function } \\
\hline No & - & - & 1 & - & - & 1.03 & 3.06 \\
\hline Yes & 0.57 & 4.26 & 1 & 0.04 & 1.78 & & \\
\hline \multicolumn{8}{|l|}{ Social function } \\
\hline No & - & - & 1 & - & - & 0.12 & 0.89 \\
\hline Yes & -1.10 & 4.76 & 1 & 0.03 & 0.33 & & \\
\hline \multicolumn{8}{|l|}{ Average duration of each use } \\
\hline$<30 \min$ & - & - & 1 & - & - & 1.19 & 3.52 \\
\hline$\geq 30 \mathrm{~min}$ & 0.72 & 6.78 & 1 & 0.009 & 2.05 & & \\
\hline \multicolumn{8}{|l|}{ Education level } \\
\hline High school or secondary school & -0.96 & 4.28 & 1 & 0.04 & 0.04 & 0.15 & 0.95 \\
\hline Undergraduate or college & -1.04 & 5.61 & 1 & 0.02 & 0.35 & 0.15 & 0.84 \\
\hline Master's and above & -1.32 & 7.25 & 1 & 0.007 & 0.27 & 0.10 & 0.70 \\
\hline Constant & 1.82 & 2.38 & 1 & 0.12 & 6.19 & - & - \\
\hline
\end{tabular}

${ }^{\mathrm{a}} d f$ : degrees of freedom.

\section{Discussion}

This study was a cross-sectional survey carried out in Changsha, China, which revealed that the usage of acAPPs was very high (930/1304, $71.40 \%$ of the participants had used one) and frequent (457/930, 49.4\% of the users used it 1-2 times per day) among pregnant women in urban areas. After controlling for several confounding factors, functions and duration of the use of acAPPs during pregnancy were found to be related to the incidence of antenatal depression. This reminds us that when considering pregnant women's health education, it is important to look beyond traditional pregnancy schools and maternal and child special education and recognize the usefulness of acAPPs as mobile medicine is expected to become a new means of health education and management during pregnancy $[9,31,32]$. At the same time, acAPP design can be optimized by adding functions, such as disease screening, peer communication, and time reminders, to increase population coverage for pregnant women and mental health care.

This study revealed 4 important aspects of the use of acAPPs. First, it confirmed that mobile apps are becoming major ways to obtain health information [33]. Research in Australia [12] involving 410 women has found that nearly three-quarters of women used pregnancy-related apps and that most of them used these apps at least once a week. A Chinese study [6] found that $78.81 \%$ of expectant mothers downloaded pregnancy-related apps. These results are similar to our findings in terms of acAPP usage rate. Compared with traditional methods of information acquisition, antenatal care apps make it possible for pregnant women to find pregnancy care knowledge at their own time, free from the restrictions of work, life, transportation, and family environment, via broad availability of smartphones and network coverage. This could help save health service costs $[34,35]$.
Second, just as the literature [12] has shown, pregnant women with different characteristics use acAPPs differently. In this study, family income, place of residence, education, first pregnancy, planned pregnancy, having no previous children, and opportunity to communicate with pregnant women of the same age affected the usage of acAPPs. These findings suggest that we should tailor the design of acAPPs to meet the characteristics of pregnant women. Furthermore, as vulnerable groups (older, lower income and education, and unplanned pregnancies) in general tend to use acAPPs less, acAPPs would need to be better designed to reach these populations.

Third, the process of selecting an acAPP is different from routine health care decisions that are more influenced by health care professionals. Most pregnant women rely on user evaluations to select acAPPs rather than professional recommendations, which makes it particularly important for acAPPs to be professional and accurate in terms of information content. In contrast to other entertainment apps, user evaluations of acAPPs are often comments on user-friendliness, and they do not discuss professionalism, accuracy, or comprehensiveness. Studies have shown that if the pregnancy information shared by apps is inaccurate and unreliable, users of these apps face risks in terms of pregnancy protection [36]. The regulation of health acAPPs is an important issue raised in the existing research [37,38]. There are also studies $[39,40]$ suggesting that the incorporation of a medical editorial team can increase the reliability of the knowledge provided in acAPPs in order to meet the requirements of information demanders.

Finally, acAPPs may be designed to monitor and intervene in perinatal depression [41]. This study found that scores for depression were higher in pregnant women who focused on using the acAPP's disease-screening functions. This may be because this group of pregnant women had underlying diseases 
or anxieties about their own health, leading their depressive symptoms to be more pronounced. The pregnant women who preferred acApps with social functions had a desire for communication, and the use of acAPPs also increased the opportunities for communication with other pregnant women and channels of release. Pregnant women can receive mutual support and comfort [42], rendering them relatively less at risk of depressive symptoms. Studies have confirmed that peer communication is a protective factor for depressive symptoms [43]. Interestingly, the study also found that depressive symptoms were more pronounced in pregnant women who used acApps for more than half an hour. This may be because such pregnant women are isolated from the real world or have obstacles in their interpersonal relationships, leading to their immersion in the Internet [44]. This is consistent with the findings of Mansourian et al [45]. Augner et al [46,47] also found that overuse of smartphones is one of the predictors of adolescent depression. This suggests that when developers design acAPPs, proper tools, such as adding a time-use reminder function, may help users arrange rest time. AcAPPs with disease-screening functions that provide health consultations and psychological guidance could reduce the risk of antenatal depression. Adding related content and functions to acAPPs would also make them better tools for pregnancy management.

This study is a cross-sectional survey of all expecting mothers present at the Provincial Maternal and Child Care Hospital during a selected period of time; thus, data extrapolation was limited and no causal inference could be made. In addition, the self-made questionnaires used in this study were only perfected in the pre-experiment and had not been tested for reliability and validity. There is also heterogeneity in the types of antenatal care apps. In future studies, authors should consider quality evaluation and fine classification before conducting in-depth analyses. Our team used the mystery customer approach to evaluate the acAPPs' accuracy and reliability, the results of which will be described in another article.

\section{Acknowledgments}

We would like to thank the people who have contributed to the field implementation of this study, including Liao Nianquan from Hunan Provincial Maternal and Child Health Hospital, Tianlin Ma from Peking Union Medical College. This work was supported by the National Natural Science Foundation of China (Development of a dynamic predictive model of perinatal depression integrating social-environmental, psychological and biological factors: a prospective cohort study, grant number 81402690) and National Institutes of Health/Fogarty (eCapacity Development and Growth in the Aspire Network (eC.ASPIRE), grant \#1R25TW010012).

\section{Authors' Contributions}

YM, as the first author, developed the initial manuscript. She observed the operation of the entire study. WG guided the overall design of the study, helped develop the instruments used in the study, and negotiated for program management of data and field access. DRX, JW, and XS contributed substantially to the revision and refinement of the final manuscript.

\section{Conflicts of Interest}

None declared.

\section{References}

1. Zenith. Smartphone penetration to reach $66 \%$ in 2018. URL: http://www.zenithmedia.com/ smartphone-penetration-reach-66-2018/[WebCite Cache ID 73Fwv7LBk]

2. Sydow L, Cheney S. 2017 Retrospective: A Monumental Year for the App Economy. 2018. URL: https://www.appannie.com/ en/insights/market-data/app-annie-2017-retrospective/ [accessed 2018-10-18] [WebCite Cache ID 73FxEIWke]

3. The 39th China Statistical Report on Internet Development. China Policy Review 2017 Apr.

4. Yiguan: China Mobile Medical White Paper 2017 (with download). China Mobile Medical White Paper 2017 URL: http:/ /www.199it.com/archives/574582.html [accessed 2017-03-21]

5. Pan G. The application research of pregnant m-health APP. Chongqing Medical University 2014.

6. Xiangzhou P. Research on influential factors of mom baby health management mobile APP service quality based on user experience theory. Beijing Forestry University 2015.

7. Acceptance TM, Barriers R. Patient Adoption of mHealth. China Digital Medicine 2015 [FREE Full text]

8. Tripp N, Hainey K, Liu A, Poulton A, Peek M, Kim J, et al. An emerging model of maternity care: smartphone, midwife, doctor? Women Birth 2014 Mar;27(1):64-67. [doi: 10.1016/j.wombi.2013.11.001] [Medline: 24295598]

9. Kaewkungwal J, Singhasivanon P, Khamsiriwatchara A, Sawang S, Meankaew P, Wechsart A. Application of smart phone in 'Better Border Healthcare Program': a module for mother and child care. BMC Med Inform Decis Mak 2010 Nov 03;10:69 [FREE Full text] [doi: 10.1186/1472-6947-10-69] [Medline: 21047412]

10. Wenmin Y, Jie W, Hongyu Z, Jian YOU. Investigation on Health Demands of Health Website Visitors. Journal of Nursing Science 2009;24(9):86-87.

11. Lee Y, Moon M. Utilization and Content Evaluation of Mobile Applications for Pregnancy, Birth, and Child Care. Healthc Inform Res 2016 Apr;22(2):73-80 [FREE Full text] [doi: 10.4258/hir.2016.22.2.73] [Medline: 27200216] 
12. Lupton D, Pedersen S. An Australian survey of women's use of pregnancy and parenting apps. Women Birth 2016 Aug;29(4):368-375. [doi: 10.1016/j.wombi.2016.01.008] [Medline: 26874938]

13. Pratap A, Atkins DC, Renn BN, Tanana MJ, Mooney SD, Anguera JA, et al. The accuracy of passive phone sensors in predicting daily mood. Depress Anxiety 2018 Aug 21. [doi: 10.1002/da.22822] [Medline: 30129691]

14. Jiménez-Serrano S, Tortajada S, Garía-Gómez JM. A Mobile Health Application to Predict Postpartum Depression Based on Machine Learning. Telemed J E Health 2015 Jul;21(7):567-574. [doi: 10.1089/tmj.2014.0113] [Medline: 25734829]

15. Tsai AC, Tomlinson M, Dewing S, le Roux IM, Harwood JM, Chopra M, et al. Antenatal depression case finding by community health workers in South Africa: feasibility of a mobile phone application. Arch Womens Ment Health 2014 Oct;17(5):423-431 [FREE Full text] [doi: 10.1007/s00737-014-0426-7] [Medline: 24682529]

16. Marcano Belisario JS, Doherty K, O'Donoghue J, Ramchandani P, Majeed A, Doherty G, et al. A bespoke mobile application for the longitudinal assessment of depression and mood during pregnancy: protocol of a feasibility study. BMJ Open 2017 Dec 29;7(5):e014469 [FREE Full text] [doi: 10.1136/bmjopen-2016-014469] [Medline: 28554914]

17. Faherty LJ, Hantsoo L, Appleby D, Sammel MD, Bennett IM, Wiebe DJ. Movement patterns in women at risk for perinatal depression: use of a mood-monitoring mobile application in pregnancy. J Am Med Inform Assoc 2017 Jul 01;24(4):746-753. [doi: 10.1093/jamia/ocx005] [Medline: 28339686]

18. Wenhui B, Siyuan T, Jiarui C, Yao L, Chunxiang Q, Mei S. Application of Mobile Health Technology in the Research of Postpartum Depression. Nursing Journal of Chinese People's Liberation Army 2018;5:22-26 [FREE Full text]

19. Shen N, Levitan MJ, Johnson A, Bender JL, Hamilton-Page M, Jadad AAR, et al. Finding a depression app: a review and content analysis of the depression app marketplace. JMIR Mhealth Uhealth 2015 Feb 16;3(1):e16 [FREE Full text] [doi:

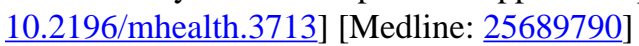

20. Lu X, Chen X. Initial exploration of pregnancy decompression APP design based on emotion needs. Design 2015:142-143.

21. Donker T, Petrie K, Proudfoot J, Clarke J, Birch MR, Christensen H. Smartphones for smarter delivery of mental health programs: a systematic review. J Med Internet Res 2013 Nov 15;15(11):e247 [FREE Full text] [doi: 10.2196/jmir.2791] [Medline: 24240579]

22. Sutter-Dallay AL, Cosnefroy O, Glatigny-Dallay E, Verdoux H, Rascle N. Evolution of perinatal depressive symptoms from pregnancy to two years postpartum in a low-risk sample: the MATQUID cohort. J Affect Disord 2012 Jun;139(1):23-29. [doi: 10.1016/j.jad.2011.08.018] [Medline: 22410506]

23. Juan H, Yu-qiong W. The relationship between antenatal depression and postnatal depression of women in Chengdu City. Chinese Journal of Nursing 2009;44(11):984-987.

24. Robertson E, Grace S, Wallington T, Stewart DE. Antenatal risk factors for postpartum depression: a synthesis of recent literature. Gen Hosp Psychiatry 2004;26(4):289-295. [doi: 10.1016/j.genhosppsych.2004.02.006] [Medline: 15234824]

25. Rahman A, Creed F. Outcome of prenatal depression and risk factors associated with persistence in the first postnatal year: prospective study from Rawalpindi, Pakistan. J Affect Disord 2007 Jun;100(1-3):115-121 [FREE Full text] [doi: 10.1016/j.jad.2006.10.004] [Medline: 17098291]

26. Wang Y, Guo X, Lau Y, Chan KS, Yin L, Chen J. Psychometric evaluation of the Mainland Chinese version of the Edinburgh Postnatal Depression Scale. Int J Nurs Stud 2009 Jun;46(6):813-823. [doi: 10.1016/j.ijnurstu.2009.01.010] [Medline: 19217107]

27. Weiqin L, Chuanlan C, Shimine C. Study on the correlation between depression and sleep quality in pregnant women. Maternal \& Child Health Care of China 2015.

28. Deave T, Heron J, Evans J, Emond A. The impact of maternal depression in pregnancy on early child development. BJOG 2008 Jul;115(8):1043-1051 [FREE Full text] [doi: 10.1111/j.1471-0528.2008.01752.x] [Medline: 18651886]

29. Teixeira C, Figueiredo B, Conde A, Pacheco A, Costa R. Anxiety and depression during pregnancy in women and men. J Affect Disord 2009 Dec;119(1-3):142-148. [doi: 10.1016/j.jad.2009.03.005] [Medline: 19346001]

30. Eberhard-Gran M, Tambs K, Opjordsmoen S, Skrondal A, Eskild A. Depression during pregnancy and after delivery: a repeated measurement study. J Psychosom Obstet Gynaecol 2004 Mar;25(1):15-21. [Medline: 15376401]

31. Little A, Medhanyie A, Yebyo H, Spigt M, Dinant GJ, Blanco R. Meeting community health worker needs for maternal health care service delivery using appropriate mobile technologies in Ethiopia. PLoS One 2013;8(10):e77563 [FREE Full text] [doi: 10.1371/journal.pone.0077563] [Medline: 24204872]

32. Kahn JG, Yang JS, Kahn JS. 'Mobile' health needs and opportunities in developing countries. Health Aff (Millwood) 2010 Feb;29(2):252-258. [doi: 10.1377/hlthaff.2009.0965] [Medline: 20348069]

33. Daly LM, Horey D, Middleton PF, Boyle FM, Flenady V. The effect of mobile application interventions on influencing healthy maternal behaviour and improving perinatal health outcomes: a systematic review protocol. Syst Rev 2017 Dec 08;6(1):26 [FREE Full text] [doi: 10.1186/s13643-017-0424-8] [Medline: 28179012]

34. Hearn L, Miller M, Lester L. Reaching perinatal women online: the Healthy You, Healthy Baby website and app. J Obes 2014;2014:573928 [FREE Full text] [doi: 10.1155/2014/573928] [Medline: 24872891]

35. Moore J. The benefits of mobile apps for patients and providers. British Journal of Healthcare Management 2012 Sep;18(9):465-467. [doi: 10.12968/bjhc.2012.18.9.465]

36. Deng Y, Liu W, Tong-Xuan LI, Law DO. Discussion on the Current Running Status of Mobile Medical APP and Relevant Legal Regulatory Issues. China Medical Devices 2015. 
37. Peng W, Hao W. Mobile Internet Medical Application Status and Future Development Trend of Domestic and Abroad. China Digital Medicine 2014:8-10.

38. Xue L, Jia YJ, Pang SL. A survey on knowledge of prenatal care of 300 pregnant women. Maternal \& Child Health Care of China 2007.

39. Yi LI. Functions of domestic interrogation mobile medical APP. Chinese Journal of Medical Library \& Information Science 2015.

40. Derbyshire E, Dancey D. Smartphone Medical Applications for Women's Health: What Is the Evidence-Base and Feedback? Int J Telemed Appl 2013;2013:782074 [FREE Full text] [doi: 10.1155/2013/782074] [Medline: 24454354]

41. Osma J, Barrera AZ, Ramphos E. Are Pregnant and Postpartum Women Interested in Health-Related Apps? Implications for the Prevention of Perinatal Depression. Cyberpsychol Behav Soc Netw 2016 Jun;19(6):412-415. [doi: 10.1089/cyber.2015.0549] [Medline: 27327069]

42. Johnson SA. "Maternal Devices", Social Media and the Self-Management of Pregnancy, Mothering and Child Health. Societies 2014 Jun 13;4(2):330-350. [doi: 10.3390/soc4020330]

43. Chopra R, Punia S, Sangwan S. Depression and Peer-Relationship among Adolescents in Haryana. Studies on Home and Community Science 2016;10(1-3):21-25. [doi: 10.1080/09737189.2016.11885362]

44. Chen BF, Chen YJ, Zhu Y. Association of mobile phone addiction and functional impairment and depression among college students. Chinese Journal of School Doctor 2015.

45. Mansourian M, Solhi M, Adab Z, Latifi M. Relationship between dependence to mobile phone with loneliness and social support in University students. Razi Journal of Medical Sciences 2014.

46. Augner C, Hacker GW. Associations between problematic mobile phone use and psychological parameters in young adults. Int J Public Health 2012 Apr;57(2):437-441. [doi: 10.1007/s00038-011-0234-z] [Medline: 21290162]

47. Yen C, Tang T, Yen J, Lin H, Huang C, Liu S, et al. Symptoms of problematic cellular phone use, functional impairment and its association with depression among adolescents in Southern Taiwan. J Adolesc 2009 Aug;32(4):863-873. [doi: 10.1016/j.adolescence.2008.10.006] [Medline: 19027941]
Abbreviations
acAPPs: antenatal care apps
EPDS: Edinburgh Postnatal Depression Scale

Edited by G Eysenbach; submitted 06.07.18; peer-reviewed by P Akhtar, SFA Shah, I Adam; comments to author 15.08.18; accepted
28.08.18; published 29.11.18
Please cite as:
Mo Y, Gong W, Wang J, Sheng X, Xu DR
The Association Between the Use of Antenatal Care Smartphone Apps in Pregnant Women and Antenatal Depression: Cross-Sectional
Study
JMIR Mhealth Uhealth 2018; $6(11):$ : 11508
URL: $\underline{\text { http://mhealth.jmir.org/2018/11/e11508/ }}$
doi: $10.2196 / 11508$
PMID: $\underline{30497996}$

(C) Yushi Mo, Wenjie Gong, Joyce Wang, Xiaoqi Sheng, Dong R Xu. Originally published in JMIR Mhealth and Uhealth (http://mhealth.jmir.org), 29.11.2018. This is an open-access article distributed under the terms of the Creative Commons Attribution License (https://creativecommons.org/licenses/by/4.0/), which permits unrestricted use, distribution, and reproduction in any medium, provided the original work, first published in JMIR mhealth and uhealth, is properly cited. The complete bibliographic information, a link to the original publication on http://mhealth.jmir.org/, as well as this copyright and license information must be included. 